\section{Como as ações de saúde pensam o homem e como - homem as repensa: uma análise antropológica do controle da doença de Chagas}

\author{
How health activities view man and how man \\ rethinks them: an anthropological analysis \\ of Chagas disease control
}

\author{
${ }^{1}$ Universitá di Bologna, \\ Bologna, Italia. \\ 2 Centro de Pesquisas René \\ Rachou, Fundação Oswaldo \\ Cruz, Belo Horizonte, Brasil. \\ 3 Faculdade de Medicina, \\ Universidade Federal de \\ Minas Gerais, Belo Horizonte, \\ Brasil. \\ Correspondência \\ E. D. Gontijo \\ Departamento de Medicina \\ Preventiva e Social, \\ Faculdade de Medicina, \\ Universidade Federal de \\ Minas Gerais. \\ Av. Alfredo Balena 190, sala \\ 825, Belo Horizonte, $M G$ \\ 30130-100, Brasil. \\ egontijo@medicina.ufmg.br
}

\begin{abstract}
This anthropological study addresses the cultural perceptions of a group of residents in the city of Bambui, Minas Gerais State, Brazil, in relation to experience with Chagas disease and the impact of health measures on social life. The ethnographic study was based on open interviews, seeking to identify individual perceptions among $35 \mathrm{in}$ habitants of Bambui (with and without Chagas disease) living in the region since the 1940s, when Chagas disease control activities were launched. Within a broad analysis of social perceptions concerning the effect of these health measures, the study sought to observe the cultural representations of the illness process. The study is intended to contribute to comprehensive work in health interventions, including the target population's socio-cultural characteristics. The cultural perspective plays an important role in preventing social distress.
\end{abstract}

Chagas Disease; Communicable Disease Control; Cultural Anthropology
Claudia Magnani 1

João Carlos Pinto Dias 2

Eliane Dias Gontijo 3

\section{Introdução}

A doença de Chagas, desde sua descoberta, é reconhecida pela complexa inter-relação dos fatores biológicos, históricos, políticos e sócioeconômicos.

Sem a intenção de abordar os demais aspectos sociais que se demonstraram elementos determinantes para a difusão da doença de Chagas $1,2,3$, pretende-se, neste trabalho, refletir sobre a questão sócio-cultural ligada à experiência da doença, em residentes no Município de Bambuí, Minas Gerais, Brasil.

A escolha desse recorte revela-se interessante ao se constatar que essa região participou de etapa fundamental na história da luta contra a tripanossomíase e foi cenário do reconhecimento da doença de Chagas no ambiente científico, assim como na vida social da população bambuiense. Do momento em que a região foi reconhecida como foco endêmico de doença de Chagas, nos anos 1940, essa passou a ser terreno de importantes conquistas nos âmbitos de vigilância e luta antitriatomínica, no controle dos bancos de sangue e nos avanços teóricos de conhecimento da patologia. Com a instalação do CEPMC (Centro de Estudos e Profilaxia da Moléstia de Chagas) em 1943, sob a direção de Emmanuel Dias, construíram-se ali os primeiros modelos de combate à doença, enfocados no controle vetorial.

$\mathrm{O}$ presente estudo se interessou em avaliar a percepção das intervenções sanitárias realizadas 
entre os anos 1940 e 1960, por parte de indivíduos chagásicos e não chagásicos que viveram em Bambuí, naquela época, e, ainda hoje, permanecem na região.

\section{Metodologia}

A metodologia utilizada neste estudo é de tipo etnográfico e baseia-se no instrumento qualitativo da entrevista aberta semi-estruturada, orientada às narrações da experiência de adoecimento e à percepção coletiva da doença e das ações de luta. As perguntas básicas da entrevista focalizaram os seguintes aspectos: o grau de consciência da população entrevistada sobre as ações de luta contra a doença; as formas de compreensão das noções e das práticas trazidas pelo serviço de saúde; o papel desenvolvido pelos indivíduos dentro do programa sanitário; a percepção da doença de Chagas, dentro das simbologias e das práticas locais.

A população entrevistada compõe-se de vinte e cinco indivíduos chagásicos, portadores da forma cardíaca, e de outros dez indivíduos não chagásicos, todos entre 44 a 77 anos, que viveram na região rural de Bambuí, na época delineada acima, onde foram promovidas as ações sanitárias e residem, ainda hoje, na área urbana do município.

As entrevistas foram realizadas no Centro de Pesquisas René Rachou, Fundação Oswaldo Cruz (CPqRR/FIOCRUZ) de Bambuí, em local reservado, assegurando privacidade e conforto aos participantes, no período entre março e junho 2008. O trabalho foi aprovado pelo Comitê de Ética em Pesquisa, Universidade Federal de Minas Gerais (COEP/UFMG; processo Etic. 095/05).

\section{Ações de pesquisa, controle e luta promovidas em Bambuí}

Com a fundação do CEPMC (1943), foram planejadas e aplicadas ações de controle e de luta antitriatomínica na região rural do Município de Bambuí. A primeira providência do Instituto foi recensear e classificar as habitações (segundos as tipologias: mocambo, térreo, sobrado) e os habitantes (recolhendo dados sócio-demográficos) do território definido para os trabalhos. Secundariamente, fez-se o levantamento da presença de triatomíneos (vetores da tripanossomíase), mediante método de captura, e foram promovidos exames que verificassem o índice de contaminação pelo parasito, enquanto se experimentavam inseticidas. As informações levantadas durante essas fases registraram um quadro alarmante: $40 \%$ das casas rurais encontravam-se infestadas por barbeiros, dos quais, cerca de $30 \%$ mostravam-se infectados pelo parasito ${ }^{4}$. Após essa fase preparatória, de mapeamento do território e levantamento geográfico de triatomíneos, foi promovida uma etapa de ataque, com ações de borrifação (de inseticidas) e pesquisa domiciliar de triatomíneos. Finalmente, promoveu-se a vigilância, que envolvia, e até hoje continua envolvendo, em parte, a participação comunitária. Para manter o controle sobre os vetores, foi instalada uma rede de centros informativos referenciais (gerenciados também por líderes locais) para a notificação da presença nos domicílios 5,6. A interrupção da doença, registrada nos anos setenta, evidencia o sucesso dessas ações 7,8,9.

Entretanto, não se tratou somente de combater uma infecção na comunidade local, o que estava em jogo era o reconhecimento da doença como um problema mais amplo de saúde pública. De fato, outro objetivo dos pesquisadores do CEPMC foi demonstrar a validade da tripanossomíase americana que, na época, encontrava a reticência da comunidade cientifica quanto à sua importância e gravidade para a população brasileira e latino-americana. Paralelamente ao esforço visivelmente destinado à profilaxia da doença, desenvolveram-se, para essa finalidade, importantes estudos sobre os aspectos clínicos da patologia, os quais procuravam incrementar o conhecimento clínico da doença. Resultados desses esforços foram: a certificação e a legitimação da tripanossomíase americana 10, finalmente definida como entidade nosológica específica, e a participação do governo no planejamento de intervenções em escala nacional e internacional 11,12.

\section{As ações de saúde e o pensamento do homem como "ser biológico"}

Sem possibilidade de produzir uma vacina e sem um tratamento específico que tivesse alcançado eficácia significativa, as ações pioneiras desenvolvidas pelo CEPMC, em Bambuí, direcionaram-se à vigilância dos espaços domiciliar e peri-domiciliar, com o objetivo de eliminar o inseto vetor, considerado, então, o elo mais frágil da corrente de transmissão do parasita Trypanosoma cruzi.

Reconhecendo a importância dessa iniciativa, volta-se aqui a atenção para um lado do fenômeno de doença que está por trás do quadro epidemiológico: a experiência social. $\mathrm{O}$ que se discute neste trabalho é o fato de não se ter alcançado a mesma eficácia do controle vetorial em termos de bem-estar social, visto que a doença criou sofrimento individual e coletivo. 
A análise da estratégia sanitária que está na base das práticas realizadas em Bambuí - assim como na maioria das áreas endêmicas do país onde se operaram programas institucionais de controle - mostra como o enfoque exclusivo dado à transmissão da doença orientou ações, educação e participação comunitária. Não obstante, tentou-se criar largos espaços de ação e decisão para a "população-alvo" (com tarefas de competência e decisão), articulando um plano de cooperação entre agentes locais (professoras rurais e funcionários públicos da prefeitura) e agentes institucionais (Superintendência de Campanhas de Saúde Pública - SUCAM) 7, o combate contra os barbeiros estava modelado nos Programas Verticais do Ministério da Saúde, os quais restringiam a dimensão pedagógica do processo participativo às noções e práticas de prevenção como: o esclarecimento sobre o vetor, o alerta contra o perigo de transmissão da doença, a responsabilização do indivíduo sobre a própria participação na luta antitriatomínica e a incorporação de práticas higiênicas para a proteção da saúde pessoal e coletiva.

"A guerra contra o barbeiro" se impôs enquanto foco privilegiado para a resolução do problema sanitário, demonstrando a exclusiva perspectiva entomológica. Sem a intenção de diminuir sua relevância, a estratégia sanitária é entendida aqui como limitada, quando restrita a esse aspecto "mapeável" da enfermidade. Efetivamente, o esforço destinado à interrupção da transmissão legitimou o problema somente dentro do plano biológico - "objetivo" - e negligenciou as outras dimensões políticas, econômicas e, como examinadas aqui, sócio-culturais, profundamente ligadas à doença.

"De los tres elementos que forman parte de la transmisión de la enfermedad: el parasito que la produce, el vetor que la transmite y el hombre que la sufre, tenemos abundante información sobre los dos primeros; pero muy poco sobre el hombre" 1 (p. 29).

Teoricamente, se a saúde é entendida como "um estado de completo bem-estar físico, mental e social, e não meramente a ausência de doença ou incapacidade" 13 (p. 1), as ações para a saúde deveriam se ocupar também das dimensões "não orgânicas" do mal-estar.

Não obstante as limitações ligadas à sua forma teórica, esse conceito supera a definição "biológica" de saúde e reconhece as dimensões sociais, econômicas, políticas, que determinam o bem-estar do homem 14 .

As ações sanitárias tendem a pensar o homem apenas em sua dimensão biológica, com a ótica de tratar de "corpos doentes". Contudo, a dimensão da doença não se resolve simples- mente na esfera fisiológica, sendo também uma experiência humana relacionada a uma particular realidade histórica e cultural. É nesse sentido que as atividades promovidas em Bambuí revelaram-se eficazes ao focalizarem, exclusivamente, objetivos entomológicos, mas demonstraram-se simplificadas na medida em que desconheceram os mais amplos efeitos derivados da própria ação nas diferentes esferas socioculturais da "população-alvo".

O homem foi pensado como "ser biológico" e foi extraído de suas redes sociais e de suas simbologias culturais. A discussão central deste estudo pretenderá levar em consideração o impacto das ações de saúde dentro do sistema cultural da população de Bambuí, tendo, como base, a idéia de que a doença significa algo para o indivíduo somente após um processo de simbolização, seja biomédico, seja popular ou construído socialmente.

"Seria ilusório supor que apenas a primeira ordem de fatores (biológica) produz um estado 'objetivo' de saúde, que depois é 'subjetivamente' interpretado pela sociedade. Estar doente implica sempre num dado comportamento do afetado, que é condicionado tanto pelo estado do organismo como pelo modo como este estado é socialmente percebido" 15 (p. 73).

A análise do impacto global das ações de saúde deve considerar as significações populares da tripanossomíase no momento em que essas condicionam ativamente o estado de saúde da população. Nesse caso, os valores da doença de Chagas se definiram socialmente em torno de pólos negativos e contrastaram o beneficio trazido pelas ações implementadas.

\section{A doença como fato social}

Quando os serviços de saúde se inseriram entre a sociedade e o meio ambiente com a finalidade de controlar os fenômenos biológicos responsáveis pela transmissão da doença, esses provocaram modificações na realidade, introduzindo novas organizações simbólicas e práticas. Mas o processo que os acompanharam foi mais amplo; o ingresso da "biomedicina", com suas práticas e valores, na comunidade bambuiense. O termo "biomedicina" refere-se ao conceito dado por Kleinman 16 à medicina ocidental, para distingui-la de outras medicinas não ocidentais e para defini-la conceitualmente como etnomedicina, ou seja, sistema médico culturalmente orientado segundo princípios específicos, centrados nas dimensões biofísicas do corpo e da saúde. Retornando ao nosso caso, a biomedicina representou, então, uma inovação terapêutica para a 
comunidade bambuiense da primeira metade do século XX, pois essa contava, exclusivamente, com a oferta de cura das medicinas "popular" e "folk"; as primeiras exercidas por anciões (detentores da sabedoria em torno ao uso de "remédios caseiros" a base de plantas, ervas e chás), as segundas, por curadores ou benzedores (os quais ofereciam uma cura num plano humano mais abrangente, atribuindo a causa da doença a questões sócio-culturais e não só biológicas). Testemunhando esse processo histórico, umas senhoras entrevistadas relatam a própria experiência das práticas de cura, antes da chegada dos novos serviços de saúde: "Lá não conhecia nada, nem médico minha filha! O povo vivia assim, fazia chá quando sentia as coisas, ficava aquele pálido, aquela dor, aquela dor de barriga, eles pegavam ramos de roça, qualquer ramozinho, ramo de fazer chá, hortelã, às vezes Santa Maria, que eles falavam que era pra a gente que tinha verme" (Senhora F/06).

Frente ao contexto local, com suas representações específicas do mundo, assim como da saúde e da doença, o que foi produzido pela intervenção da comunidade biomédica foi, antes de tudo, "conhecimentos" e "comportamentos". Pensados a partir do universo cultural biomédico, esses novos elementos se inseriram na sociedade, que, até então, os desconhecia, sendo reelaborados segundo o código simbólico local. Partindo dessas reflexões, é possível repensar as formas pelas quais a doença de Chagas - como palavra e como diagnose - entrou e passou a fazer parte da população de Bambuí.

\section{"Quando você morava na roça, sabia o} que era a doença de Chagas?"

"Não entendia, porque a gente trabalhava na roça. Devido à cidade, a gente começou a consultare saber! Quando mudei para cá, descobri este negócio de chagas, soube..." (Senhora F/06).

"Porque o povo era tudo bobo, não fazia exame de nada, e se sentia muito sadio" (Senhora $\mathrm{M} / 12)$.

Não pode se negligenciar o fato que, mesmo com o objetivo de combatê-la, de certa forma, o serviço médico trouxe a doença para a sociedade. E a tripanossomíase entrou na comunidade bambuiense mais como fato social do que biológico, pois, a partir do momento em que um elemento externo entra em uma dada rede social, esse é incorporado de forma própria pela população e investido de significações morais e culturais próprias.

Nesse sentido, transmitir o conhecimento de uma doença não é um ato "neutro", mas um ato social que cria conseqüências na realidade em que esse opera, pelo simples fato de que a doença, como qualquer outra coisa, não é algo "natural" ou "dado", sendo, antes de tudo, uma realidade construída simbolicamente 17 na coletividade (dentro das relações sociais), a partir de representações locais (histórico-culturais) do mundo. Por esse motivo, a doença de Chagas não foi percebida pela população bambuiense da mesma maneira como ela foi classificada pela comunidade científica. E esse hiato, entre os dois sistemas simbólicos, deixou que os valores culturais da doença, que aprofundaremos em seguida, afirmassem-se como únicas referências da população para compreender a doença.

\section{A simbologia popular da doença de Chagas: como o homem repensa as ações de saúde}

"A análise sociológica de como a doença é socialmente aprendida não nega a visão biológica e psicológica da medicina, mas a amplia e complica. A visão médica do acometimento do organismo pode diferir amplamente da percepção leiga" 15 (p. 73).

A partir do próprio "sistema explicativo" 16, cada uma das linguagens culturais - popular e científica - constrói a própria interpretação da doença. No encontro com os indivíduos que participaram da pesquisa, avaliou-se um específico domínio cultural em relação à experiência da doença de Chagas e à percepção das intervenções sanitárias perpetradas, o qual não coincide com a explicação científica.

A transmissão das informações conduzida pelos serviços sanitários passou por certos caminhos de recorte, seleção e requalificação, que se desenvolveram na relação entre emissor e receptor. Primeiramente, a mensagem abordou somente alguns dos conteúdos do processo do adoecer (centrando-se no momento da transmissão, sem tratar dos percursos de adoecimento) e, secundariamente, ela foi recebida ativamente, reapropriada e reorganizada a partir de outra rede semântica. Passando por esses processos interpretativos, a doença de Chagas foi sendo associada a uma série de valores que emergem no discurso popular, às vezes aproximando-se, outras se afastando do discurso biomédico e criando, assim, uma maneira peculiar de lidar com a doença. Na amplitude da fala dos entrevistados, destacaram-se dois domínios culturais definidos sobre a enfermidade; um primeiro discurso simbólico em torno do mecanismo de transmissão e do controle; e um segundo em relação aos próprios valores da doença.

- A transmissão: o saber em relação à contaminação da doença é certamente o que mais en- 
contra acordo com os valores do paradigma científico. Avaliou-se que os indivíduos distinguem o barbeiro como portador do parasito e causa de infecção do homem e reconhecem as condições estruturais da casa de pau-a-pique como fatores de infestação domiciliar dos triatomas. Além de compartilhar essas noções, quase a totalidade dos indivíduos entrevistados relatou experiências de convivência com o barbeiro no domicílio. Alguns se recordam da borrifação de inseticidas, e outros participaram ativamente das ações de captura e vigilância de barbeiros.

“Eles falavam que existia o barbeiro, que a gente tinha que ter cuidado porque sempre ia em casa de barro, onde tinha muita parede que tinha buracos, que eles entravam e ficavam ali. Antes andavam para as roças assim jogando remédio nas casas, pra combater" (Senhor A/05).

"O povo falava do barbeiro; o comentário era que o barbeiro chupava e dava a doença. De vez em quando, eles passavam lá, da SUCAM, eles só procuravam o barbeiro e jogavam o remédio nas casas. Todo mundo sabia que tinha o barbeiro $e$ que eles vinham jogar o remédio... Mas não sabia bem o que era esta doença..."

\section{"O que eles explicavam?"}

"Nada, só pediam licença pra procurar e encontrar o barbeiro" (Senhor R/08).

A relação imediata entre "doença de Chagas" e "barbeiro" e o conhecimento dos riscos a ele associados enquanto vetor de doença são índices de um intenso trabalho que focalizou práticas e noções sobre o pólo preventivo da enfermidade. O intenso esforço feito para o combate ao vetor emerge visivelmente na experiência da população com a doença, nos comportamentos e nas idéias compartilhadas na vida coletiva. Foi incorporada uma consciência nova sobre a própria responsabilidade em relação à defesa da saúde e à luta contra o vetor, assim como práticas destinadas à prevenção da doença.

Não foi percebido o que estava ocorrendo na história da luta contra as doenças infecciosas; o que representou aquele momento para o desenvolvimento de estratégias nacionais e internacionais de combate da tripanossomíase, mas as pessoas compreenderam as ações concretas, destinadas à eliminação do barbeiro, e as incorporaram em suas representações e em seus comportamentos de forma como elas foram pensadas (foi bem demonstrada a eficácia obtida pela participação comunitária nas fases de controle vetorial).

Foram criadas uma nova relação com o meio ambiente; uma percepção diferente das condições higiênicas da casa; uma nova visão em torno do barbeiro individuado como portador de doença, e um outro olhar foi projetado nas paredes rebocadas e dentro do espaço domiciliar, na procura do inseto.

"Meu pai tinha muito cuidado com a gente porque falavam que era uma doença muito perigosa. Eu cheguei a conhecer aquele bichinho lá no chão, às vezes de noite, olhando nas paredes. Eu o achava bem engraçado, quando era pequena, porque o bichinho é tão engraçado, às vezes eu até matava barbeiro com meu pai, que falava: 'Aquele bichinho é perigoso, filha! Aquele bicho pode te morder!' Então pegava chinelo, pegava um pedaço de pau e batia, batia, batia e matava..." (Senhora J/13).

"'Eu tenho medo de morrer por causa do barbeiro!' Sempre a família toda falava isso. E os meus pais sempre falavam assim: 'se vocês achar o bichinho ai, vocês mostrem! Que é um barbeiro das costas vermelhas"” (Senhora C/04).

"Eu acredito que antigamente o povo era desconsiderado com as casas, ninguém importava assim, com a casa boa, com uma boa limpeza. $O$ povo não cuidava de limpar, não tinha muito capricho. É culpa nossa, do povo mesmo" (Senhora $\mathrm{M} / 12$ ).

As intervenções sanitárias (de borrifação e educação), atuadas pelos agentes de saúde no território rural, favoreceram um processo pedagógico direcionado à aprendizagem de atitudes e noções de prevenção sanitária e de responsabilização coletiva frente à doença. Fruto desses esforços de controle, práticas e idéias se articularam na comunidade, criando um novo modo de agir e repensar a doença.

A doença: os valores populares da tripanossomíase definiram-se em torno de um sentimento social de medo. Quando foram chamadas a discutir sobre a tripanossomíase (sobre como ela se desenvolve no corpo, sobre as conseqüências que pode trazer, ou as possibilidades de tratamento), os indivíduos entrevistados recorreram a um conhecimento baseado muito mais nas noções populares do que nas referências biomédicas. As categorias culturais compartilhadas às quais os indivíduos se referiam para classificá-la foram: "doença do barbeiro", "perigosa", "que ataca o coração", "que mata”.

"Eles falavam que a doença era perigosa, que podia matar" (Senhor A/05). "Sempre o pessoal falava que se o barbeiro picasse e chupasse na gente levava à morte” (Senhora C/04). "Falavam que dava bloqueio no coração” (Senhora A/09).

A importância de compreender as representações culturais da doença de Chagas se impõe para entender, de modo mais complexo, a realidade de quem vive cotidianamente com a "doença do barbeiro”. De fato, é errado pressupor 
que a nossa realidade seja igual à do outro, pois não existe uma realidade "única e verdadeira", mas existem realidades, cada uma definida a partir de uma crença coletiva ${ }^{18}$. Dirigir o olhar para as pessoas, para os seus mundos locais e as suas visões da realidade torna-se um exercício fundamental para identificar as questões e os problemas que afetam suas vidas e, assim, suas saúdes 2. A doença, por sua vez, é um fenômeno que deve ser visto também por como ele age na vida individual e coletiva, e por como ele gera sofrimento "fora do corpo". No caso considerado, os símbolos aos quais a doença de Chagas é associada criaram certo mal-estar, coletivo e individual, e mecanismos sociais de exclusão, porque, com a consciência da infestação dos espaços da vida cotidiana, por vetores portadores de doença considerada mortal, criou-se medo dentro das casas, assim como dentro dos corpos. A forma como a comunidade lida com a doença construiu-se em cima do medo da morte, criando conflitos sociais, assim como estigma.

"Principalmente pra quem trabalha na roça. Falam: 'Ele é chagado!' Não pode trabalhar que passa mal! Aí você perde o trabalho. Que eles têm medo que um chagado cai no chão e morre, que dá problema" (Senhor R/28).

"E se amanhã não consigo mais agüentar o trabalho? O que será? Parece que, não sei como, não sei porque, mas é como se tivesse tirado da gente o direito de ser feliz" (Senhora E13).

\section{O rito da diagnose: a transformação da identidade}

“A gente que está doente não presta pra nada. A gente não é mais como era quando não tinha aparecido ainda a doença. A pessoa doente é muito triste. Deus me livre!" ( Senhor R/30).

A tripanossomíase americana se distingue, no discurso biomédico, por constituir uma patologia de caráter enigmático, uma vez que é pouco reconhecível pelos seus sintomas e que assume diferentes formas patológicas no corpo do indivíduo. Segundo essa classificação, o processo de doença é caracterizado por diversas fases de gravidade (aguda, crônica, indeterminada) e formas clínicas (cardíaca, digestiva, mista). Do seu ponto de vista, a comunidade local associa a doença indistintamente ao risco de morte súbita, ao mesmo tempo em que reconhece o coração como alvo único da doença. Não se encontra, nas narrativas dos entrevistados, a percepção das diversas formas clínicas, nem das diferentes gravidades que podem caracterizar a doença; as possíveis variáveis clínicas, a forma assintomática e as possibilidades de tratamento não foram integradas dentro do seu sentido social. No discurso popular, a classificação da doença assumiu uma identidade dicotômica, focando a questão em "ser chagásico" ou não o ser.

Nomeada (e por isso "posta a existir") e conclamada pelas suas conseqüências "perigosas", a doença não foi, ao mesmo tempo, explicada e discutida horizontalmente com a comunidade. Dessa forma, a tripanossomíase foi resignificada unicamente a partir dos valores percebidos pela população, os quais se tornaram mais eficazes e difundidos para a sua decodificação.

Os significados culturais não se afirmaram por acaso, mas a partir do específico processo de intervenção promovido, o qual, com o fim de criar uma pressão social e conscientizar a ação coletiva na luta contra a patologia e com o objetivo centrado no combate vetorial, enfatizou a gravidade máxima da doença sem construir um diálogo sobre os seus valores. Se, de um lado, essa percepção pode ter contribuído para uma resposta mais rápida e eficaz da população frente à emergência, de outro, deixou um vazio importante em torno dos significados da doença, que foi preenchido a partir da experiência local, articulando-se em torno aos caracteres percebidos, os quais, muitas vezes, agiram nas redes sociais como limitadores simbólicos e instrumentos de discriminação.

"Os símbolos ligados à doença de Chagas criam repercussões de ordem social que superam as fronteiras biológicas e a tornam um fenômeno de ordem sócio-cultural. Os mitos, os significados culturais, os valores negativos que definem a doença no âmbito popular acarretam conseqüências psicológicas e sociais que limitam a vida dos indivíduos portadores da enfermidade" 19 (p. 1631).

"A gente dizia que quem tinha Chagas parava de ser uma pessoa normal, que era uma pessoa não normal, que aquele problema era a coisa pior pra nossa vida. Era isso que o povo dizia: "Ah! Tem Chagas?! Já era! Acabou!" (Senhor A/01).

O processo de educação, controle e luta foi centrado no aspecto da prevenção da doença ainda não transmitida e não se ocupou da doença já existente na sociedade. O enfoque dado pelos serviços de saúde foi "combater a doença", e não "organizar uma convivência com ela". Houve insuficiente esforço direcionado à compreensão da relação entre a sociedade e a doença, no momento em que esta última já fazia parte dela, e, por isso, a convivência com a tripanossomíase se articulou dentro das diretrizes simbólicas que foram traçadas pela experiência local, ou seja: que a pessoa chagásica estava destinada à morte e que não podia mais exercer seu papel social dentro da comunidade. 
Se por um lado, o sistema biomédico diagnosticou a doença de Chagas, por outro, não forneceu à população quadros conceituais adequados para interpretá-la. O enfoque unidirecional ao vetor deixou "distâncias sem pontes" com os próprios doentes, e esses se viram constrangidos a lidar com um processo de crise que estava reconhecido "biologicamente" e decodificado "socialmente". Incorporada pela sociedade rural como uma ameaça social e coletiva, o diagnóstico da doença trouxe discriminações para os afetados, em seu potencial produtivo e em sua participação social.

“Alguém pode ser vítima de uma agressão do meio natural, ao se tornar, por exemplo, hospedeiro de um agente infeccioso, mas só se torna doente quando, em conseqüência desta agressão, o seu comportamento se transforma e ele é reconhecido como enfermo pelo seu meio social" 15 (p. 69).

A partir de critérios populares de avaliação da realidade, foi produzida uma "situação social de doença” dentro da experiência local, que se desenvolveu a partir do reconhecimento clínico (diagnóstico) da enfermidade.

"Tudo muda na vida de uma pessoa depois que de repente ele descobre que é "chagado". Tive insegurança, passei até doença de pânico" (Senhora J/13).

"Ficava pensando assim: 'acabou minha vida"” (Senhora A/3).

"Vou até te falar verdade, porque eu tenho esta doença de Chagas, mas eu não penso que a tenho. Porque se a gente for pensar que tem a doença de Chagas a gente fica mais doente!" (Senhora H/2).

A interpretação de sinais corpóreos como sintomas mórbidos é um processo que, servindo-se do código cultural/biomédico e de peculiares processos de análise do corpo, torna o diagnóstico da doença um ritual social pelo fato de exercitar uma função transformativo/performática que muda, de forma irreversível, a identidade do indivíduo, da "pessoa sadia" à "chagásica”. Passando pelo rito da diagnose, o episódio de doença se constrói simbolicamente segundo dois processos culturais: pelo lado científico, a localização da patologia no corpo legitima a enfermidade como evento biológico (confinado à dimensão orgânica), pelo indivíduo, ela se torna uma experiência de crise que aborda todas as dimensões (não biológicas) de vida. A partir da nova identidade "biomédica", o indivíduo deve, de fato, reorganizar a própria existência e a posicionar-se de forma nova na sua realidade.
"Você acha que desde que foi descoberta

a sua doença houve melhoria, estabilizou ou piorou?"

"Eu acredito que foi pior. Porque quando você não sabe é como se você não tivesse a doença. (...) Porque agora você vive sempre com aquele negócio: 'Eu sou chagada, sou chagada, sou chagada!' Mas por um lado foi melhor porque eu estou me tratando. É bom e ao mesmo tempo é ruim. Porque é bom se você está se cuidando, mas às vezes o susto te coloca mais doente, porque você fica sempre com aquilo na cabeça'” (Senhora J/13).

Se, de um lado, a comunidade biomédica traz uma nova proposta de cura - um conhecimento diferente sobre o corpo e os processos da doença, outros medicamentos e práticas diagnósticas -, do outro, reconhece doenças novas e as individualiza nos corpos. Esses corpos, porém, inseremse em redes sociais dentro das quais são resignificados com valores locais e vão sendo colocados no centro de processos discriminatórios.

"Eu tinha medo de tirar o sangue, fiquei nervosa, comecei a chorar, fiquei com medo de morrer e deixar os meus filhos pequenos, que todo mundo falava que a Chagas era perigosa, que podia morrer de repente" (Senhora $\mathrm{T} / 15$ ).

Uma vez identificado como "chagásico", o indivíduo se faz portador solitário do próprio corpo doente, assumindo as representações culturais a esse associadas. $\mathrm{O}$ adoecimento cria um conflito na experiência pessoal, que força o homem a lidar, de forma nova, com o seu mundo de sempre. É neste terreno de ação humana que os símbolos da doença de Chagas agem. O que mais parece prejudicado para o sujeito chagásico é o exercício do seu papel dentro da comunidade e das redes sociais, sobretudo no âmbito das relações de trabalho e das tarefas domésticas.

\section{"O que o médico lhe explicou?"}

"Pediu pra não trabalhar, não pegar serviço pesado, não esforçar...” (Senhor R/08).

"A gente que é mais antiga não fica quieta; limpa, cozinha, esfrega. Não tem aquele sentimento de aquietar" (Senhora F/6).

A dispensa das tarefas, aconselhada pelos médicos, revela-se um fator de crise para os indivíduos, seja por razões de ordem econômica ou por razões sociais, para a exigência de desenvolver o próprio papel social.

Para enfrentar esse tipo de sofrimento social, revela-se necessário trazer a discussão biomédica para o plano da sociedade, de forma que se torne possível criar um confronto e um vínculo entre ambas as organizações de idéias e práticas em torno dos conceitos de saúde/doença/cura. 
O esforço de compreensão cultural é tarefa que não deve ser negligenciada, sobretudo nas campanhas de saúde que lidam com grupos sociais que não compartilham o mesmo sistema simbólico (biomédico). Revela-se importantíssimo criar laços entre saberes para conseguir estender pontes de comunicação entre os diferentes mundos locais 20. A figura do "mediador cultural" parece importantíssima para exercer essa função dialógica. Nesse sentido, revelou-se crucial, por exemplo, o papel do médico na relação com o paciente chagásico. Partindo de alguns relatos, foi possível entender que, no momento em que o profissional se demonstrou atento à escuta do paciente e à troca de idéias em relação à experiência de adoecimento, ele conseguiu renegociar os símbolos populares que criam sofrimento psicológico e social. As pessoas que tiveram um acompanhamento adequado de médicos e de outros profissionais de saúde com maior freqüência, preocupados em explicar e escutar, atentos à forma pela qual a doença é percebida, apresentaram mais oportunidades de redefinir a convivência com a própria situação de saúde de modo consciente e confiante e adquiriram maior segurança na visão das próprias possibilidades de vida.

Os programas de atenção ao paciente chagásico devem agir para minimizar as conseqüências biológicas tanto quanto as repercussões sociais da doença de Chagas 21, servindo-se, de um lado, dos recursos terapêuticos da biomedicina e, do outro, procurando um diálogo com a pessoa doente, que, a partir do confronto das referências culturais, atue nas redes simbólicas. O homem, certamente, beneficia-se do conhecimento e da troca de informações, enquanto uma abordagem não adequada ao fator de crise pode trazer sofrimento individual e coletivo, desconfiança, desespero e estigma social.

\section{Conclusões}

As questões de saúde, de uma maneira geral, têm sido tratadas muito mais com perspectivas técnicas, epidemiológicas, biomédicas, políticas, do que a partir de um interesse pela dimensão social da relação do homem com aquela. O presente estudo quis abordar esse último aspecto a partir da experiência que um grupo de pessoas teve com o fenômeno da tripanossomíase americana e com as ações desenvolvidas pelos serviços de saúde para combatê-la. Registrou-se, aqui, como a doença de Chagas se definiu em torno de um saber popular que não encontrou suficiente troca com a cultura biomédica, criando outros valores e significados em relação à experiência corpórea de adoecimento, os quais, em parte, cons- truíram formas de estigma social. Esse processo sócio-cultural torna evidente como as ações de controle promovidas na região foram pensadas a partir de uma cultura que compartilha as referências biomédicas e que pensa a doença como fato biológico individual, negando, dessa forma, a sua análise cultural e as relações sociais dentro das quais é construída. As práticas sanitárias não repercutem apenas nos planos ambientais ou epidemiológicos, mas atingem a sociedade, introduzindo práticas e símbolos com os quais cada um se confronta, criando, necessariamente, novos cenários de vida. Na organização de intervenções sanitárias, a comunidade "alvo" deve ter papel não somente nas ações, mas também deve ser procurado um diálogo nas várias etapas de planejamento, discutindo comportamentos e conceitos.

A avaliação das ações de saúde promovidas na comunidade de Bambuí concentrou-se nas formas por meio das quais se comunicaram as práticas e as informações sobre o corpo, a saúde, a doença, a terapia. Certamente as campanhas educativas feitas no campo se demonstraram eficazes, propondo atividades que foram incorporadas pela população em seus hábitos e pensamentos. Entretanto, o que está aqui sendo discutido é o conteúdo desse diálogo, o qual foi focalizado somente na transmissão da enfermidade, privilegiando preocupações entomológicas e biológicas e excluindo as dimensões sociais.

O contraste entre os dois saberes (biomédicopopular) deixou a população local com uma fragilidade de conhecimento biomédico em relação à doença que contribuiu para criar uma relação de sofrimento entre o homem e o próprio corpo doente e entre o homem doente e a sociedade.

Nesse sentido, é relevante que as ações de saúde se preocupem com a troca de conhecimentos culturais em torno dos processos de saúde e doença, tendo como finalidade mostrar uma possível convivência com a patologia, e não somente uma possível luta contra ela.

A incorporação de práticas e idéias sobre as possibilidades de tratamento sintomático, as perspectivas de vida e a benignidade da maioria das apresentações clínicas constituiria um novo universo de valores a partir do qual a população poderia criar um processo semântico diferente em torno da experiência de doença. Perspectivas dialógicas "horizontais" do acompanhamento médico poderiam auxiliar a comunidade a não focalizar a patologia somente nas suas conseqüências mais graves (cardiomegalia e morte súbita) - responsáveis pelo sofrimento social e marginalização do doente - além de conscientizá-la sobre melhores possibilidades de vida, que podem ocorrer com e apesar da doença. 


\section{Resumo}

Estudo antropológico sobre a percepção cultural de um grupo de residentes no Município de Bambuí, Minas Gerais, Brasil, em relação à experiência de doença de Chagas e ao impacto das ações de saúde na vida social. Foi realizada uma pesquisa etnográfica baseada no instrumento de entrevista aberta, buscando identificar a percepção individual de 35 habitantes de Bambuí (chagásicos e não) que viveram na região desde os anos quarenta, quando as ações de saúde foram promovidas para combater a doença de Chagas. Dentro de uma ampla análise da percepção social do efeito das ações de saúde implementadas, procurou-se observar as representações culturais do processo do adoecer. O estudo pretende contribuir para que as intervenções de saúde possam atuar de forma integral, incluindo os aspectos sócio-culturais com a população à qual se dirigem. A perspectiva cultural assume um importante papel para evitar sofrimento social.

Doença de Chagas; Controle de Doenças Transmissíveis; Antropologia Cultural

\section{Colaboradores}

C. Magnani participou do planejamento do estudo, da coleta de dados, análise e redação do artigo. J. C. P. Dias participou do planejamento do estudo e revisão do artigo. E. D. Gontijo participou do planejamento do estudo, análise e redação do artigo.

\section{Agradecimentos}

Este trabalho foi realizado com o apoio do Centro de Pesquisas Renné Rachou, Fundação Oswaldo Cruz, Belo Horizonte e de Bambuí. Agradecemos à contribuição de todas as pessoas que participaram das entrevistas e aos funcionários do Centro de Pesquisas de Bambuí, especialmente Paulo Acácio Lamournier e Aparecida Donizete de Oliveira Vargas, amiga atenciosa, pelo apoio no desenvolvimento do trabalho. 


\section{Referências}

1. Briceño-León R. La casa enferma, sociología de la enfermedad de Chagas. Caracas: Fondo Editorial Acta Científica de Venezuela/Consorcio de Ediciones Capriles C.A.; 1990.

2. Dias JCP, Borges-Dias R. Aspectos sociais, econômicos e culturais da doença de Chagas. Ciênc Cult Supl (São Paulo) 1979; 31 Suppl:105-17.

3. Dias JCP. Doença de Chagas, ambiente, participação e Estado. Cad Saúde Pública 2001; 17 Suppl: 165-9.

4. Dias E. Um ensaio de profilaxia de moléstia de Chagas. Rio de Janeiro: Imprensa Nacional; 1945. p. 9-18.

5. Silveira AC. Programação da Campanha de Controle da Doença de Chagas no Brasil. In: Universidade de Brasília, organizador. Situação e perspectivas do controle das doenças infecciosas e parasitárias. Brasília: Universidade de Brasília; 1981. p. 285-90. (Cadernos da UnB).

6. Carneiro M, Antunes CMF. Avaliação de eficácia do Programa de Controle da Doença de Chagas: aspectos metodológicos. Cad Saúde Pública 1994; 10 Suppl 2:261-72.

7. Dias JCP, Borges-Dias R. Participação da comunidade no controle da doença de Chagas. In: Universidade de Brasília, organizador. Situação e perspectivas do controle das doenças infecciosas e parasitárias. Brasília: Universidade de Brasília; 1981. p. 293-312. (Cadernos da UnB).

8. Akhavan D. Analise de custo-efetividade do programa de controle da doença de Chagas no Brasil. Brasília: Organização Pan-Americana da Saúde/ Organização Mundial da Saúde; 2000.

9. Dias JCP, Silveira AC, Schofield CJ. The impact of chagas disease control in Latin America - a review. Mem Inst Oswaldo Cruz 2002; 97:602-12.

10. Kropf SP, Azevedo N, Ferreira LO. Biomedical research and public health in Brazil: the case of Chagas' disease. Soc Hist Med 2003; 16:111-29.
11. Morel CM. Chagas disease, from discovery to control - and beyond: history, myths and lessons to take home. Mem Inst Oswaldo Cruz 1999; 94 Suppl 1:3-16.

12. Kropf SP. Doença de Chagas, doença do Brasil: ciência, saúde e nação (1909-1962) [Tese de Doutorado]. Niterói: Universidade Federal Fluminense; 2006.

13. World Health Organization. Constitution of the World Health Organization. New York: World Health Organization; 1946.

14. Corbellini G. Breve storia delle idee di salute e di malattia. Roma: Carocci; 2005.

15. Singer P, Campos O, Oliveira EM. Prevenir e curar: o controle social através dos serviços de saúde. Rio de Janeiro: Editora Forense Universitária; 1988.

16. Kleinman A. Concepts and a model for the comparison of medical systems as cultural systems. Soc Sci Med 1978; 12:85-93.

17. Taussig M. Reification and the consciousness of the patient. Soc Sci Med 1980; 14:3-13.

18. Briceño-León R. Siete tesis sobre la educación para la participación. In: Barata RB, Briceño-León R, organizadores. Doenças endêmicas: abordagens sociais, culturais e comportamentais. Rio de Janeiro: Editora Fiocruz; 2000. p. 233-50.

19. Magnani C, Oliveira BG, Gontijo ED. Representações, mitos e comportamentos do paciente submetido ao implante de marca-passo na doença de Chagas. Cad Saúde Pública 2007; 23:1624-32.

20. Martinez AH. Etnografía y educación para la salud. Hacia un modelo dialógico de intervención. Trabajo Social y Salud 1999; 34:173-88.

21. Uchôa E, Firmo JOA, Dias EC, Pereira MSN, Gontijo ED. Signos, significados e ações associados à doença de Chagas. Cad Saúde Pública 2002; 18:71-9.

Recebido em 19/Ago/2008

Versão final reapresentada em 04/Mar/2009 Aprovado em 16/Abr/2009 